\title{
A DUPLA HERMENÊUTICA DA SOCIOLOGIA DA EDUCAÇÃO: A EDUCAÇÃO DAS NOVAS GERAÇÕES E A ORGANIZAÇÃO ESCOLAR
}

Marcelo Baumann Burgos

Doutor em sociologia (luperj/Ucam), professor do Departamento de Ciências Sociais da PUC-Rio e pesquisador da Fundação Caed. E-mail: burgos@puc-rio.br

Orcid: 0000-0001-9766-8848

http://dx.doi.org/10.1590/0102-049076/110

Há muito ruído no diálogo entre sociologia e educação quando o assunto é escola. Sociólogos costumam ser acusados, muitas vezes com justiça, de ter uma relação instrumental com a escola, relação esta recorrentemente estudada para demonstrar alguma hipótese externa a ela, desde a reprodução da desigualdade até a segregação urbana. Nesse caso, as instituições educacionais, e em especial a escola, tendem a ser esvaziadas de suas especificidades, afigurando-se mais como parte do método da pesquisa do que como objeto.

O contrário também é verdadeiro: a educação tende a instrumentalizar a sociologia, quase sempre contornando o sentido mais amplo de suas indagações sobre a relação entre a educação e as dinâmicas e conflitos sociais. Pratica-se, por assim dizer, uma espécie de escolarização da sociologia, fazendo dela um recurso para a construção de respostas aplicadas aos problemas escolares.

Uma boa forma de representação e de problematização desse ruído é a sugerida pelo sociólogo argentino Néstor López (2005), ao delimitar uma fronteira nítida entre o que denomina de "sociologia da reprodução" e de "otimismo pedagógico". A "sociologia da reprodução" tipifica a forma 
com que uma certa sociologia hegemônica se apropria do objeto educação escolar, vendo nele uma engrenagem organizada para a reprodução de estruturas sociais desiguais. Em sua versão mais influente e sofisticada, formulada por Bourdieu e Passeron (1992), o sistema educacional converte-se em uma engrenagem de reprodução cultural e social que, por meio de processos caracterizados como violência simbólica, transforma desigualdade social em desigualdade escolar, e esta em formas desiguais de distribuição de capital simbólico, cultural, social e econômico.

Por seu turno, "otimismo pedagógico" denota a crença no poder da administração escolar como fator capaz de reverter dificuldades oriundas de contextos sociais adversos em relação às chances de escolarização. A emergência dessa corrente representa, como sustenta López, uma espécie de reação à impotência administrativa da escola subjacente à abordagem sociológica dominante. Se na "sociologia da reprodução", 50 a escola pouco pode fazer frente a uma estrutura social desigual que a coloniza para se reproduzir, o "otimismo pedagógico" realça, ao contrário, a força da escola, mirando o foco no poder transformador da gestão. Ainda que não tenha sido essa a intenção principal de López, podemos tomar esses dois tipos ideais de concepção da relação da escola com a sociedade como uma boa aproximação em face das disputas que atravessam a relação entre as áreas da educação e da sociologia. Para o argumento do presente artigo, importa menos essa disputa entre as duas áreas de conhecimento, e seus desdobramentos em posições acadêmicas e políticas, do que o fato de que ela tem trazido prejuízos acadêmicos e práticos importantes, que nos remetem à discussão sobre os contornos e o alcance da sociologia da educação. ${ }^{1}$

1 Cabe esclarecer que consideramos conveniente evitar a noção de campo, para não confundi-la com o conceito consagrado por Bourdieu (2003), para quem seu significado pressupõe a delimitação de fronteiras que talvez fossem difíceis de demarcar quando se trata da área da educação no Brasil. 
A "sociologia da reprodução" chegou a ser muito influente na área da educação, mas, na medida em que afasta a abordagem sociológica dos desafios práticos da escola, ameaça a aliança constitutiva da área da educação com seus profissionais. Daí a reação que se segue à hegemonia dessa forma específica de sociologia da educação, e que ajuda a explicar por que parte da área da educação abraçaria uma concepção gestora da relação da escola com seu público, muito devedora das novas conexões estabelecidas entre a ciência da administração e a estatística aplicada aos sistemas de avaliação de resultado escolar. Não por acaso, o "otimismo pedagógico" nasce resistente à influência dos fatores propriamente sociológicos, tais como classe, raça, ecologia urbana, entre outros.

López (que fala a partir de estudo empírico realizado em escolas de países andinos) vai ao ponto quando associa a clivagem entre as duas abordagens ao fenômeno que denomina como "brecha da educabilidade", com o qual pretende indicar o grau de distância frequentemente existente entre o projeto escolar e as especificidades de seu público. A brecha seria uma espécie de desdobramento concreto da polarização estabelecida na abordagem acadêmico-política. De um lado, uma sociologia da educação que tende a se deter no contexto (pouco importando no caso se por contexto entendemos a estrutura social ou a ecologia do lugar), fazendo da escola nada mais do que epifenômeno da sua socio-lógica; de outro, uma perspectiva administrativa e pedagógica radicalizada na crença na capacidade da gestão escolar de produzir uma espécie de blindagem em relação ao contexto. Desta última perspectiva, surge uma abordagem dessociologizada e dessociologizante da escola, da qual são evidências importantes noções como "clima escolar" e "efeito escola". A escola é pensada como um ambiente, cuja qualidade pode ser melhor ou pior conforme os padrões de gestão adotados. Com isso, as noções sociológicas básicas 
perdem lugar, ou são neutralizadas: relação entre gerações, classe e status, sexo, religião e raça, tudo se torna secundário em face das técnicas organizacionais. Uma boa gestão escolar seria capaz de se sobrepor às "dificuldades contextuais".

López propõe superar essa clivagem por meio de uma abordagem relacional, articulando as duas pontas da educabilidade: as dimensões interna e externa à escola. Para isso, seria necessário, de um lado, considerar a capacidade da própria escola para lidar com seu aluno real - em vez de lamentar não poder contar com seu aluno ideal, que já "chega educado" para o jogo escolar; e de outro, formular políticas intersetoriais capazes de minimizar a incidência de fatores externos sobre as condições de educabilidade, tais como questões envolvendo saneamento, saúde, segurança pública, transporte, entre outras.

A proposta oferecida por López é importante, abrindo espaço para uma agenda muito clara de ações interdependentes, na escola e fora dela. É verdade que ele deixa intocado o aspecto teórico de fundo, o qual identifica, mas não se propõe a aprofundar. Ao apresentar a antinomia entre as duas vertentes, no entanto, o sociólogo argentino consegue demonstrar como as áreas da sociologia e da educação se afastam e se convertem em domínios epistemológicos distintos e até conflitantes, fazendo romper, com isso, o elo que o patriarca da sociologia da educação, Émile Durkheim, havia fixado.

De fato, ao se centrar na denúncia crítica do trabalho escolar, encarando-o como engrenagem reprodutora de desigualdades sociais, a "sociologia da reprodução" rompe com algo importante da conexão classicamente proposta por Durkheim (1968), quando defende que cabe à sociologia o estudo do padrão de relacionamento entre gerações, e de como os adultos transmitem às crianças sua herança cultural, contribuindo, assim, para conformar consensos lógicos e morais; daí a sua compreensão de que seria tarefa fundamental da sociologia fazer o estudo crítico da pedagogia, 
de modo a torná-la compatível com os consensos fundamentais da sociedade em seu tempo. Não custa lembrar que é por essa via que Durkheim, em seu livro A evolução pedagógica na França, aplica seu método histórico comparado para sustentar sua defesa de uma "pedagogia realista" como a mais adequada à sua sociedade contemporânea (Durkheim, 1995).

Por seu turno, ao se deixar embalar pela crença em teorias das organizações desidratadas de princípios sociológicos, a educação afastar-se-ia de uma abordagem mais compreensiva da escola, correndo o risco de se entregar à métrica estrita da busca por metas e resultados.

Quando reduz a dois tipos ideais as formas dominantes e polares de compreensão do lugar e do papel da escola, López tem o mérito de realçar diferenças disciplinares, que demarcam distintas perspectivas de análise, agendas de pesquisa e projetos de reforma. No limite, para a "sociologia da reprodução", a reforma da escola precisa ser antecedida por uma reforma da sociedade; ao passo que, para o "otimismo pedagógico", o protagonismo é da própria escola, e a cultura da gestão pressupõe que ela (a escola) possa ser compreendida como uma espécie de subsistema.

Mas a resposta formulada por López ao problema teórico é de ordem puramente prática. Pois o efeito perverso dessa fratura entre a sociologia e a educação seria o aprofundamento da brecha da educabilidade. Com isso, ele desloca a centralidade do problema teórico em favor de uma agenda de reforma, orientada para a mudança das condições externas e internas à escola com vistas a tornar o estudante mais bem preparado para a atividade escolar. Diversamente, nosso propósito neste artigo é justamente o de iluminar aquilo que em López é subsumido, na medida em que ele assume como dado que as áreas da sociologia e da educação se separaram e se reconfiguraram, e que o melhor que se poderia esperar, a partir de então, seria uma articulação entre as duas abordagens por meio de políticas 
intersetoriais. Com isso, a abordagem própria à sociologia da educação dissolver-se-ia.

O problema é que essa forma de conceber a questão acaba por não levar em conta a própria forma como sociologia e educação foram se definindo uma em relação à outra, e de como, para que o "otimismo pedagógico" pudesse emergir, foi necessário um trabalho de redefinição de um terceiro campo, o da ciência da administração, também ela emancipada de suas matrizes sociológicas. Em meio a essa espécie de revolta contra a sociologia, que vai ganhado força em especial a partir dos anos de 1970, de modo concomitante à crise dos Estados do bem-estar social, e que em boa medida é impulsionada pela forma como a própria sociologia se isola em um terreno pouco responsivo aos problemas escolares, as áreas da educação e da ciência da administração se aproximam, conformando a nova linguagem da gestão escolar.

O efeito mais sensível desse processo é a afirmação de uma concepção tecnocrática da educação escolar, que afastou a escola não apenas do mundo do aluno, como sustenta López, mas também da dimensão fundamental a qualquer sociedade, que diz respeito à reflexão sobre o sentido mais abrangente do trabalho de formação das novas gerações. A ênfase no modelo tecnocrático assume como um dado que a sociedade já tem resolvido seu projeto para as novas gerações, retirando-o do terreno dos conflitos sociais e culturais em que ele se enraíza. Os riscos dessa redução são evidentes. Em casos como o brasileiro, por exemplo, em nome de uma escola que efetivamente ensine, pode-se perder de vista o compromisso escolar com a formação da cultura democrática. No limite, poder-se-ia até mesmo propor, como já tem ocorrido entre nós, que uma escola militarizada produziria melhores resultados do que uma escola exposta aos conflitos inerentes a um ambiente que cultiva a cultura de liberdade. 
Mas essa alternativa fatalmente desfaz o elo entre a escola e o projeto democrático.

Felizmente, a onda do "otimismo pedagógico" e sua conexão com um modelo mais tecnocrático vêm sendo criticadas e transformadas. Uma boa evidência disso aparece no Second International Handbook of Educational Change (Hargreaves et al., 2010), livro que reúne mais de quarenta autores de diferentes partes do mundo. Em suas mais de mil páginas, o Handbook organiza um debate que, a nosso ver, sintetiza as mudanças pelas quais a imaginação reformista no campo da educação vem passando desde a primeira década do século XXI. A partir de suas experiências como pesquisadores, profissionais da educação, consultores ou ainda implementadores de políticas públicas, os autores que participam dessa coletânea apresentam distintas possibilidades de mudança educacional, mas convergem em torno da aposta na iniciativa e criatividade individual dos profissionais da educação, bem como no investimento em sua formação. Não se trata apenas de uma questão tática, mas, sim, de uma compreensão de que a mudança não pode ser concebida a partir de cima, em abstrato, sendo necessário valorizar o contexto e a participação. Em suma, o desafio focalizado por essa literatura seria o de como conciliar reforma educacional de larga escala, voltada para a melhoria da aprendizagem, com uma abordagem democrática que oriente o processo de mudança e valorize o envolvimento da comunidade escolar. ${ }^{2}$

É precisamente aqui que se pode situar a proposta deste artigo, de pôr em foco a necessidade de se reconstruir a relação entre as áreas da sociologia e da educação. Pretendemos propor uma nova concepção de sociologia da educação, que remonte às raízes clássicas da proposta durkheimiana, mas que assuma uma outra feição na medida

2 Para um aprofundamento desse debate, ver Burgos e Bellato (2019). 
em que parte da premissa de que ela deve ser compreendida segundo a "dupla hermenêutica" de que fala Giddens (2013, p. XXXVII): "Uma interação interpretativa mútua entre ciência social e aquelas cujas atividades constituem seu objeto de estudo".

Apropriada para a sociologia da educação, a dupla hermenêutica nos faz entender esse campo de estudo como uma abordagem que pensa o lugar social da educação - em seu papel de estruturar a relação entre adultos e as novas gerações - como indissociável da prática levada a cabo pelas instituições de ensino, com seus desafios de fazer valer aquilo que se espera delas, a saber: ensinar e educar. "As teorias e descobertas nas ciências sociais", afirma Giddens, "são suscetíveis de ter consequências práticas (e políticas) independentemente de o observador sociológico ou o estrategista político decidir que elas podem ou não ser aplicadas a uma dada questão prática” (Giddens, 2013, p. XL).

A noção de "dupla hermenêutica" traz à cena, portanto, a responsabilidade social das abordagens sociológicas, cujos efeitos nunca são completamente previsíveis, mas nunca completamente imprevisíveis. A relação da sociologia com seu objeto, afirma Giddens, é atravessada por uma "dupla hermenêutica" justamente por exigir "um duplo processo de tradução ou interpretação", o do conhecimento que os atores já portam em seu cotidiano, reduzindo-o a descrições sociológicas, e o do próprio efeito prático do conhecimento sociológico (Giddens, 2013, p. 335).

De modo mais específico, quando aplicada ao universo mais estrito de uma sociologia da educação escolar, levar em conta a "dupla hermenêutica" obriga a que se considerem as múltiplas dimensões sociológicas atinentes à educação escolar que essa área de conhecimento encerra. Em vez de pretender fixar um ponto analítico externo à educação escolar, como faz a "sociologia da reprodução" com a noção de "estrutura social", assumindo-a como referência 
analítica objetiva, uma sociologia da educação, consciente de sua "dupla hermenêutica", está atenta à importância de a "pesquisa social ser sensível às habilidades complexas que os atores possuem para coordenar os contextos de seu comportamento cotidiano" (Giddens, 2013, p. 336).

Dessa perspectiva, a sociologia da educação escolar pode ser encarada como um feixe que articula múltiplas escalas e dimensões de questões, a começar pelo estudo das relações entre gerações e, muito especialmente, das relações que se estabelecem entre estudantes e professores no espaço escolar. Para esse tipo de estudo, também pode interessar pesquisar a relação da escola com a vizinhança, o bairro e a cidade, daí a sociologia urbana se tornar um campo de estudos tão presente para a sociologia da educação; do mesmo modo, interessa pensar as famílias, suas condições de ocupação profissional, suas moralidades e práticas religiosas etc.

Mas como não existe escola sem currículo e sem didática, a sociologia da educação deve também ser concebida como uma sociologia do conhecimento aplicada a esses constructos que constituem a organização escolar, inevitavelmente atravessados por conflitos técnicos, os quais mal escondem suas raízes sociais e culturais. Finalmente, a sociologia da educação escolar também deve ser pensada como uma sociologia das organizações, e aqui entram em cena aspectos caros à sociologia da administração, que dizem respeito à gestão escolar e à relação da escola com outras instituições.

Pensar a sociologia da educação escolar a partir dessas múltiplas sociologias é também reconhecê-la como uma área de síntese, que reúne três principais vertentes, a saber: a da natureza das relações entre adultos e as novas gerações; a do tipo de conhecimento e experiência que os adultos, enquanto educadores, pretendem ensinar; e a forma pela qual a escola está organizada para estruturar 
essas relações. Nesse sentido, se a nossa proposição faz sentido, ganha renovada importância a reflexão sobre como essas diferentes sociologias que a sociologia da educação sintetiza se influenciam mutuamente, e de como elas constituem circuitos de articulação entre teorias e práticas que interagem, de modo vivaz, com o senso comum escolar. A ruptura entre sociologia, educação e administração, exemplarmente expressa nos dois tipos ideais formulados por López, denota com nitidez, ao menos pelo contraste que produz, as repercussões que podem ter uma sociologia que se afasta de seu compromisso com os desafios práticos da escola, abrindo espaço para uma concepção de gestão escolar exclusivamente centrada em princípios tecnocráticos. Não é o caso de aprofundar essa discussão, mas apenas de reter que essa separação entre a escola, ela mesma, e a forma de socialização tipicamente escolar é oportuna ao propósito de chamar atenção para o que há de ilusório na definição de fronteiras muito claras entre os fatores internos à escola e os fatores tradicionalmente tratados como externos a ela (Vincent, Lahire e Thin, 2001). Bem mais promissor é pensar como essas dimensões se atravessam, gerando novas contradições e desafios para a forma como as sociedades se propõem a educar as novas gerações.

Rearticular o interno e o externo à escola seria, portanto, o ponto de partida para a reformulação de uma agenda para uma sociologia da educação. A fim de demonstrarmos o possível rendimento analítico dessa proposta teórica, elegemos três eixos que consideramos fundamentais para a reflexão sobre a relação da sociedade brasileira contemporânea com a escola, a saber:

1. a afirmação da educação escolar como um valor;

2. a relação entre o direito da criança e a escola; 
3. o impacto da chegada dos pobres à escola e a produção de novas formas de desigualdade.

A delimitação desses três eixos, entre outros que poderiam ser selecionados, já carrega um significado inerente ao tipo de agenda que a sociologia da educação, a nosso ver, deveria priorizar. Não cabe aqui aprofundarmos cada um desses pontos da agenda; pretendemos tão somente demonstrar como a discussão sobre o lugar da educação básica na sociedade brasileira exige um tipo de reflexão que atravesse as fronteiras normalmente estabelecidas entre as áreas da sociologia e da educação (bem como a da ciência da administração), e como, nesse cenário, assume-se, conscientemente, o compromisso da sociologia com a importância da escola para as novas gerações, na forma de instrumento fundamental para a construção da democracia no país.

Convém revelar, nesse momento, uma inspiração importante para nossa proposta, que nos vem daquele tipo de trabalho intelectual que Guerreiro Ramos (1965) consagrou como a "redução sociológica", a qual pressupunha, entre outros aspectos, uma postura atenta às armadilhas das importações de agendas de pesquisa juntamente com suas teorias. "Nos países periféricos, a ideia e a prática da redução sociológica somente podem ocorrer ao cientista social que tenha adotado sistematicamente uma posição de engajamento ou de compromisso consciente com seu contexto" (Ramos, 1965, p. 105).

Com base nesse tipo de proposta epistemológica para delimitação de uma agenda de pesquisa em sociologia da educação, caberia perguntar, por exemplo, em que medida a sociologia da reprodução, proposta por Bourdieu e Passeron no início da década de 1970, se afigurava como uma boa entrada para pensarmos um sistema educacional excludente, que, naquele momento, começava a se abrir 
aos pobres, ao mesmo tempo que se fragilizava institucionalmente? $\mathrm{Ou}$, mais recentemente, em que medida fez sentido desembarcar com força na agenda do multiculturalismo, quando a principal ameaça ao funcionamento das escolas viria da combinação entre o processo de precarização institucional da escola e a profunda desorganização da vida popular decorrente da explosão do consumo e de uma mercantilização de seus territórios sem regulação pública (fenômeno que ocorre com mais intensidade a partir dos anos 1990, justamente quando ganha ampla difusão entre nós a discussão do multiculturalismo)? ${ }^{3}$

Lidar com a dupla hermenêutica da sociologia da educação é, de fato, tarefa urgente e complexa, quanto mais para um país como o Brasil, que tem feito notáveis avanços na ampliação do acesso à educação, mas que ainda carece de consensos fundamentais sobre como articular o mundo organizacional das escolas com o que se passa fora dela. 60 Impotência, medo, angústia e solidão! Tais são os sentimentos que, muitas vezes, definem a conduta de profissionais que, dentro ou fora da escola, lidam com educação. Em face dessa complexidade é que lançamos mão de um esforço de "redução sociológica", capaz de recortar uma agenda de pesquisa que conecte problemas centrais à sociologia com questões empiricamente importantes para o projeto escolar.

Se tivermos algum êxito em nosso propósito, o estudo desses três eixos iluminará o papel que a sociologia da educação poderá alcançar, tanto na investigação da educação escolar como dimensão importante para a compreensão do que se passa na sociedade quanto para uma contribuição mais aplicada aos desafios e necessidades da escola em seu trabalho de transformação da sociedade.

\footnotetext{
3 Para uma discussão sobre a precarização da escola ao longo das décadas de 1970 e 1980, ver Peregrino (2010). Uma boa entrada para a discussão sobre a mercantilização dos territórios populares é feita por Telles (2010) e Feltran (2014).
} 


\section{Educação escolar como um valor: a crescente adesão das famílias populares}

A educação escolar se tornou um valor popular no Brasil contemporâneo, e isso não tem nada de natural, pois é preciso lembrar que, até recentemente (não seria exagero afirmar que até a década de 1990), para boa parte das famílias populares, o projeto educacional de seus filhos era, no mínimo, objeto de muitas dúvidas e incertezas; às vezes, de ter de escolher, dramaticamente, qual filho iria seguir nos estudos, e qual iria ingressar mais precocemente no mundo do trabalho. Para muitas famílias, essa escolha nem sequer era posta, valendo, em muitos casos, a máxima do "se souber ler e escrever, já está bom”, com o que se recusava o projeto de uma escolaridade longeva para os filhos.

Cada vez mais, as famílias populares vêm acreditando na importância da escola, não apenas como parte da estratégia para uma melhor inserção profissional, mas também como dimensão fundamental da própria subjetividade. Quando uma mãe diz a um filho, dramaticamente, que se ele não estudar "não será ninguém", é preciso ouvir nessa advertência aquilo que ela efetivamente exprime: a palavra "ninguém" evoca uma anulação social. É que a escola se converteu em dimensão existencial determinante; ela é o passaporte para a vida em sociedade.

Não se ignora que a chegada maciça dos pobres à escola pública coincide com a fuga dela de parte da classe média, a aquecer um crescente e próspero mercado de ensino privado. Tampouco se ignora que essa fuga altera o lugar social da educação pública no debate político, tornando mais invisíveis seus problemas, na medida em que, para quem tem mais poder aquisitivo, os problemas educacionais seriam resolvidos segundo a lógica do mercado. Não menos importante é o fato de que uma pequena parcela das classes média e alta da sociedade venha procurando se esquivar da escola, sustentando não precisar mais 
dela, e o movimento em defesa homeschooling é evidência disso. ${ }^{4}$ Tudo isso reflete as disputas em torno da educação escolar como um valor social e cultural, mas o principal na cena brasileira contemporânea é o fato de a escola estar no centro da vida popular. Esse processo afetou o trabalho escolar, da mesma forma que foi afetado por ele.

Para uma sociologia da educação, estudar o valor da educação, e de como ele varia segundo classes e grupos sociais, deve ser tarefa primordial. Para isso, convém começar pela problematização dos processos de transformação decorrentes da profunda mudança normativa estabelecida a partir da Constituição Federal de 1988, que, em seu artigo 227, define os direitos da criança como "prioridade absoluta", e a educação como responsabilidade da família, mas também do Estado e da sociedade. Em seguida, pelo Estatuto da Criança e do Adolescente (ECA) (Lei 8.069/1990), que atualiza o país com o que acabara de ser aprovado em assembleia da ONU, introduzindo entre nós um direito muito avançado, em uma sociedade longamente acostumada a submeter seus filhos aos desígnios dos pais e dos empregadores de crianças. Pouco tempo depois, a Lei de Diretrizes e Bases (Lei 9.394/1996) reformula a estrutura da oferta educacional, redefinindo as bases do modelo federalista na educação, atribuindo novas prerrogativas e responsabilidades aos municípios e estados na gestão do serviço público de educação.

\footnotetext{
4 Animado por famílias que alegam motivos religiosos ou simplesmente em nome do que entendem ser seu direito privado e individual, e a essa altura contando com o apoio de uma indústria crescente, que reúne editoras e empresas especializadas na venda de materiais educacionais na internet, e que pleiteia financiamento público para escolas virtuais, o movimento pelo homeschooling vem ganhando força em diferentes lugares do mundo, pondo em xeque o postulado, abraçado pela maior parte das Constituições democráticas contemporâneas, de que existe uma relação umbilical entre criança na escola e construção e reprodução de sociedades democráticas. No Brasil, o homeschooling foi objeto, recentemente, de uma ação julgada pelo STF, oriunda de um Recurso Extraordinário, que teve origem em um mandado de segurança impetrado contra ato de uma Secretaria Municipal de Educação negando solicitação de uma família para educar a filha em casa. Com o impacto da pandemia da covid-19 em 2020, pode-se esperar que o movimento pela homeschooling ganhe renovado impulso.
} 
Apesar de muito importantes, os marcos normativos, evidentemente, não podem ser tomados como fontes determinantes de explicação para o que se passa na sociedade; ao contrário, são, antes, fontes de complexificação. Escola democrática? Participação estudantil? Violência escolar? Equidade como correção da noção abstrata de mérito? Justiça escolar versus injustiça social? Direitos das crianças versus critérios de justiça escolar? Autonomia escolar versus formas de controle a partir dos sistemas de avaliação externa? Uma agenda abrangente vai ganhando corpo e se materializando em debates mais ou menos estruturados na área da educação, e que só marginalmente mobiliza a sociologia. ${ }^{5}$

Fatores externos e internos à escola se atravessam mutuamente, e o valor da educação escolar cresce na mesma proporção em que as disputas em torno da escola se acentuam. A sociedade se transforma de maneira profunda, tanto cultural quanto politicamente, em função da relação duradoura de adolescentes e jovens das classes populares com a escola. A sociologia não acompanha esse processo na justa medida. Ao contrário, tende a tomar como dado aquilo que precisaria ser problematizado. Assume, em geral, a escolarização como um serviço público mais ou menos universalizado, sem fazer do impacto social e cultural da escolarização sobre a vida das novas gerações, de um lado, e sobre a própria escola, de outro, temas centrais à sua agenda. Também chama atenção a baixa presença de estudos antropológicos valorizando o impacto cultural do letramento crescente da sociedade brasileira. Ou ainda, na linha do que propõem Vincent, Lahire e Thin (2001), do impacto da difusão da forma escolar sobre diferentes dimensões da vida do país.

Quanto a isso, o movimento de ocupação das escolas por parte de estudantes secundaristas que, entre 2015 e 2016,

\footnotetext{
5 Para uma análise da constituição da área da sociologia da educação no Brasil, e de como ela ainda está organizada de modo fragmentário e marginal no interior dos programas de pós-graduação de sociologia, ver Oliveira e Ferreira da Silva (2016).
} 
alcançou a maioria dos estados, refletiu bem essas transformações, de um lado, por indicar a presença de novos jovens na cena pública, egressos de classes populares e escolarizados, mobilizados em defesa de uma escola pública mais qualificada e mais aberta à sua participação. De outro, por sinalizar novas formas de conflito, ao fazer da escola e das redes escolares arenas de disputas políticas e culturais fundamentais. Por força do movimento, profissionais da educação se viram pressionados e, muitas vezes, constrangidos por denúncias protagonizadas por jovens que os interpelaram pela falta de transparência na gestão escolar; pela falta crônica de professores em determinadas disciplinas; por problemas de estrutura física da escola; pelo mau uso de recursos disponibilizados para a escola; pela ausência de refeições com padrão mínimo de qualidade; e, talvez o mais importante, por aspectos ligados ao currículo. Nessas ocupações, que começam no estado de São Paulo no final de 2015, 64 e que ganharam impulso ao longo de 2016 em 21 estados do país, com força particular no Paraná e no Rio de Janeiro, os estudantes postulam o direito à voz e o direito a uma escola “que faça pensar e não obedecer". Não é por acaso que reivindicam mais sociologia e mais filosofia (Campos, Medeiros e Ribeiro, 2016; Camasmie, 2018).

A sociedade se transforma pela escola e transforma a escola. O Estado investe no aprimoramento da gestão escolar, valendo-se de instrumentos tipicamente gerencialistas, tais como política de metas, sistemas de incentivos (premiação e bonificação salarial, por exemplo) e sistemas de monitoramento e avaliação em larga escala (Dusi, 2017). Por seu turno, as famílias populares se organizam para tentar assegurar o projeto escolar de longo curso (Burgos, 2014). Disso se segue a emergência de novos conflitos, que tornam o ambiente escolar mais tenso e, às vezes, hostil, mas que também oferecem novas oportunidades de aproximação da escola com seus novos públicos. Uma sociologia da educação comprometida 
com a escola deve vir em socorro de seus profissionais, contribuindo para tornar inteligíveis esses processos sociais deflagrados pela afirmação do valor educação escolar como um direito inalienável da cidadania, municiando o debate sobre currículo, bem como uma sociologia das organizações atenta às novas oportunidades de valorização da efetividade do trabalho escolar. Em suma, deve contribuir para a transformação de conflitos e contradições em oportunidades para o fortalecimento do trabalho escolar.

\section{A relação entre 0 direito da criança e a escola}

É preciso considerar que o processo de afirmação do valor educação escolar ocorre em meio a uma "virada copernicana" na base normativa que define o padrão de relacionamento entre adultos e crianças na sociedade brasileira. O Estatuto da Criança e do Adolescente é, como já se observou, um gesto ousado do legislador brasileiro, que acolhe os preceitos aprovados alguns meses antes em assembleia da ONU. O Brasil é o primeiro país a fazê-lo, introduzindo em seu projeto de democracia um padrão de relacionamento entre gerações pautado pelo reconhecimento dos direitos da criança em face dos adultos, a começar por sua própria família, mas também pela escola. O estudo sociológico do processo de decantação constitucional dos direitos da criança e do adolescente, bem como das novas agências criadas pelo ECA para a sua operacionalização, ainda não foi plenamente realizado. ${ }^{6} \mathrm{Em}$ especial quando se considera, como aponta Fulvia Rosemberg (2008), o processo de apropriação cultural dessas novas formas jurídicas em uma dimensão tão sensível para qualquer sociedade, como é a do trabalho de educação das novas gerações.

Do ponto de vista da escola, a aprovação do ECA traz enormes desafios, pois instala na relação entre adultos e

6 Para um balanço dos 25 anos do ECA, ver Unicef (2015). 
crianças um critério de justiça estranho ao padrão escolar, que se organiza segundo sua própria lógica de justiça, baseada no princípio do mérito escolar. Com isso, a relação das escolas com o ECA tem sido problemática, a começar pela dificuldade de lidar com alunos considerados "empoderados", que parecem ter mais direitos do que deveres. Por isso mesmo, não raro, o ECA tende a ser visto como ameaça às autoridades escolares. Por outro lado, a escola também tem muita dificuldade de reconhecer o quanto os atores da chamada rede de proteção dos direitos da criança, entre os quais o Conselho Tutelar e o Ministério Público, podem contribuir para o enfrentamento de seus desafios, que são muitos. ${ }^{7}$

O fato de a escola lidar com públicos muito heterogêneos, com crianças e adolescentes moradoras de territórios frequentemente atravessados por toda sorte de violência e de efeitos de segregação urbana, deveria fazer com que ela buscasse aliados fora do sistema educacional, valendo-se, para tanto, dos atores das redes de proteção. Mas não é isso que tem ocorrido. Ao contrário, o que se verifica é que, quanto mais desafiados pelas condições de vida de seus novos públicos, mais as escolas e o sistema educacional tendem a se tornar ensimesmados. Exemplo disso é a forma como as escolas trabalham com questões normalmente relacionadas à temática da violência. A violência externa, que é parte da realidade de muitos de seus alunos, chega à escola de diversas maneiras. Afinal, não é demais lembrar que o Brasil é um dos países com maior número de casos de homicídios de adolescentes em todo o mundo, e isso significa que muitas escolas lidam com alunos para os quais a morte violenta ronda suas vidas, e é bastante compreensível que

\footnotetext{
7 Essas evidências foram fartamente encontradas em pesquisa por nós realizada sobre a relação entre os atores da chamada "rede de proteção dos direitos da criança". Consideramos, além da escola, o Conselho Tutelar, as promotorias que atuam na área da infância e adolescência, e o Centro de Referência em Assistência Social (Cras). Os resultados dessa pesquisa foram consolidados em Burgos (2020).
} 
elas se sintam, com frequência, impotentes para assimilar seus efeitos. ${ }^{8}$ Porém, o resultado disso costuma ser a adoção de uma postura defensiva, que, não raro, se converte em formas de exclusão escolar, materializadas em reprovação e/ou em trajetórias de infrequência e evasão.

$\mathrm{O}$ isolamento da escola e do sistema educacional como um todo se torna mais marcante quando se considera que esse processo ocorre em contraponto à ideia de rede de proteção introduzida pelo ECA. A resposta sistêmica afigura-se, assim, como uma forma de resistência velada, embora às vezes explícita, às inovações introduzidas pela premissa de que o direito da criança deve ser defendido de forma integral, ou seja, em todas as dimensões da vida dela. Com isso, malgrado o fato de a forma jurídica ser muito avançada, a baixa adesão da escola ao ECA tende a comprometer seus melhores resultados. Será que essa postura de isolamento da escola não é, de algum modo, favorecida pelas lacunas deixadas pela sociologia da educação?

Uma sociologia da educação solidária ao projeto escolar deve contribuir para tornar mais inteligíveis as contradições e interdições que atravessam a relação entre a escola e o ECA. Deve, além disso, pôr sob sua lupa os processos administrativos e sociais que conformam a rotina escolar em sua relação com atores externos a ela.

\section{0 impacto da chegada dos pobres à escola e a produção de novas formas de desigualdade}

Para uma sociedade desigual como a brasileira, a chegada maciça das camadas populares à escola necessariamente produz efeitos não controlados sobre a estrutura das diferenças. Entre essas, uma dimensão certamente importante é a

\footnotetext{
8 De acordo com o Unicef (2019), entre 2007 e 2017, 107.270 adolescentes com idades entre 10 e 19 anos foram assassinados. Dados de 2016, também do Unicef, davam conta de que uma média de 31 crianças/adolescentes estavam sendo assassinados por dia.
} 
forma como a escola vem contribuindo para gerar um tipo novo de desigualdade entre adolescentes e jovens, muitas vezes vizinhos e oriundos de famílias com o mesmo padrão de renda, ocupação e nível escolar. É que as diferenças existentes no padrão de relação com a escola produzem desigualdades, com diferentes tipos de efeitos importantes sobre a vida dos adolescentes e jovens de classes populares. Um deles diz respeito ao que tem sido chamado de "geração nem-nem" (nem trabalha, nem estuda). Essa categoria é controversa, porque reifica um suposto vazio existencial juvenil, não reconhecendo outras formas de luta para conferir significado à vida; para os nem-nem, a vida não necessariamente passa por escola e trabalho. Apesar disso, é útil para delimitar um tipo de condição juvenil (que também inclui a faixa etária dos tecnicamente caracterizados como "adolescentes") que indicaria uma situação de desvantagem de parcela desses jovens em face de seus colegas de geração e de classe. Essa desvantagem diz respeito à relação da escolarização com o mercado de trabalho (Cardoso, 2013).

A forma desigual com que adolescentes e jovens lidam com a escola pode ser consequência da combinação de inúmeros fatores. É o que demonstra Mariana Bittar (2011), ao apresentar um bom mapa das múltiplas configurações, que, envolvendo família, vizinhança, projetos sociais, igrejas e a própria escola, pode explicar os diferentes padrões de relação com a escola, mesmo entre jovens de uma mesma classe social, entre moradores de uma mesma região.

Fato é que, no Brasil contemporâneo, estar fora da escola é um motivo fortemente determinante para o grau de risco a que se expõem adolescentes e jovens. A escola protege seus alunos de múltiplas maneiras, não apenas pelas credenciais que ela promete oferecer, mas também por assegurar algum nível de supervisão por parte de adultos treinados para esse fim; e, ainda, por garantir uma sociabilidade geracional à margem dos efeitos nem sempre desejáveis do 
lugar e/ou da família. No atual contexto brasileiro, em que o ingresso precoce no mundo do trabalho felizmente deixou de ser a porta de entrada na vida adulta para a maior parte das crianças e adolescentes, estar fora da escola ou manter com ela uma relação frágil significa estar em uma espécie de limbo social. Boa evidência disso é que quase todos os adolescentes infratores e em cumprimento de medidas socioeducacionais trazem um histórico de evasão escolar. ${ }^{9}$

Na outra ponta do problema, em chave positiva, quando parte dos estudantes de escolas secundárias se mobiliza em defesa da qualidade da escola pública, verifica-se que ao menos uma franja dos jovens das classes populares conseguiu realizar uma "penetração" em face da estrutura - para evocar categoria de Paul Willis (1991) -, enxergando o quanto a escola pode ser decisiva para seu destino. Desse ponto de vista, a ocupação das escolas foi também uma dramatização protagonizada por jovens em sua busca por se diferenciar dos demais de sua geração e para tentar fugir do destino dos "nem-nem".

Mais uma vez, a sociologia da educação pode assumir um papel fundamental na organização de uma agenda capaz de delimitar os múltiplos fatores que incidem nessas novas formas de desigualdade produzidas pela presença da escola na vida popular. Antes de mais nada, ela deve iluminar o problema, articulando dados nem sempre combinados em uma mesma análise. Especialmente importante, no caso, seria aprofundar o conhecimento sobre os nexos existentes entre os fenômenos relacionados ao sistema da

9 Dados do Sistema Nacional de Atendimento Socioeducativo (Sinase), em relatório publicado em 2006, já mostravam que, dos adolescentes em cumprimento de medida socioeducativa de internação e internação provisória, mais da metade não frequentava a escola e $90 \%$ deles não haviam concluído o ensino fundamental. Dos que cumpriam medida socioeducativa de semiliberdade, $58,7 \%$ estavam fora da escola formal antes de cometer o ato infracional. Nota técnica do Instituto de Pesquisa Econômica Aplicada (Ipea), publicada em 2015, também é bastante esclarecedora quanto a esse tema. Disponível em: https://bit.ly/3219P1H. Acesso em: 13 ago. 2020 
socioeducação, à taxa de homicídios de crianças, adolescentes e jovens, e à geração "nem-nem”. E, ainda, entender como esses fenômenos estão atravessados pela presença/ ausência da escola na vida dos jovens de carne e osso por trás dessas estatísticas.

A esse propósito, vem ao caso um estudo importante sobre as novas formas de desigualdade, realizado por Fitoussi e Rosanvallon. Os autores chamam atenção para a necessidade de uma nova cultura estatística capaz de mensurar e de iluminar fenômenos que já não podem ser identificados com base nas grades anteriores, entre outras razões porque, como afirmam, "as desigualdades intracategoriais podem, assim, passar a ser mais importantes e tão persistentes como as desigualdades intercategoriais" (Fitoussi e Rosanvallon, 1997, p. 43). Para os pesquisadores franceses, "as desigualdades novas só se observam mediante um acompanhamento seguido das trajetórias efetivas dos indivíduos". Pois são, 70 em boa medida, "desigualdades de percurso" (Fitoussi e Rosanvallon, 1997, p. 50). Provocar novas formas de produção de estatísticas, articulando dimensões que normalmente não têm sido combinadas, é uma das tarefas importantes reservadas à sociologia da educação.

O estudo dessas novas formas de desigualdade geradas pela relação com a escola é uma espécie de tema de fronteira para a sociologia da educação, pois necessariamente induz a um diálogo com aspectos ligados à cultura política, à relação com novas culturas juvenis, à relação com religião, e com questões de identidades em suas diferentes formas de expressão. Mas tem também forte relevância para as organizações escolares, interpelando-as, como defende Dubet (2008), igualmente pelo ângulo dos vencidos. Afinal, pensar no destino dos vencidos, lembra Dubet, também deve ser tarefa de uma escola que se pretenda justa.

O mais importante é que, sociologicamente, não faz sentido acusar a escola de ser excludente, responsabilizando-a 
pelo fracasso de uma parcela de seus estudantes; é preciso ir além, estudando mais a fundo como essa relação de presença/ausência da escola se combina com outros fatores externos a ela. Por outro lado, também é necessário interpelar o problema a partir de dentro da escola, valorizando a sua relação com atores que constituem as redes de proteção, como sugerido anteriormente; e iluminando a forma como ela, por processos muitas vezes rotineiros (e, por isso mesmo, invisíveis), tem contribuído, involuntariamente, para aumentar o peso da derrota dos vencidos. A escola precisa da ajuda de uma sociologia da educação comprometida com ela para lidar com essas e outras questões. Por isso, os sociólogos não devem se contentar em chegar até à sua porta; precisam entrar e pensar, com a escola, a respeito dos problemas organizacionais dela.

\section{Considerações finais}

Este artigo parte de uma já longa experiência de seu autor com estudos empíricos de diferentes tipos e distintas pretensões sobre a relação da escola e do sistema educacional com múltiplas dimensões da sociedade brasileira. É também fruto do recorrente desconforto experimentado quando diante dos sujeitos que fazem a escola, os quais, com justa razão, muitas vezes esperam por respostas mais comprometidas com os desafios práticos de seu cotidiano. Traz, além disso, uma leitura crítica da forma com a qual estudos sociológicos da educação têm se relacionado com os problemas propriamente escolares.

Para esse propósito, a noção de "dupla hermenêutica", proposta por Giddens, cumpre um importante papel, na medida em que permite jogar luz sobre a responsabilidade que a sociologia pode ou deve ter sobre as redes de significados produzidas com ela e por ela. Em um momento em que precisamos de nova inspiração para animar políticas educacionais comprometidas tanto com os desígnios da democracia 
no país quanto com os resultados escolares (propósitos, a nosso ver, inseparáveis), acreditamos ser promissor repensar a relação entre a sociologia e a área da educação. Para isso, a sociologia da educação ganha significado estratégico, como uma área que, de certo modo, precisaria se reinventar entre nós, já que, curiosamente, esteve quase sempre apropriada pela área da educação, talvez devendo ser chamada de "sociologia educacional". Não é por acaso que, na área da sociologia propriamente dita, os estudos sobre educação tenham sido fortemente dominados e subsumidos aos estudos de estratificação social e mobilidade social. Terreno baldio da sociologia, a escola, mais recentemente, tem sido ocupada por estudos de sociologia urbana, que mais usam dados escolares para sustentar teses sobre segregação urbana, violência urbana etc. do que se debruçam sobre modos de a escola lidar com essas questões, as quais têm ficado a cargo quase exclusivo da área da educação.

Buscar conferir novo prestígio à sociologia da educação não significa, por certo, reivindicar para ela uma espécie de área de competência privilegiada em relação aos demais domínios do conhecimento que atravessam o mundo da escola. Muito pelo contrário, o que se pretendeu neste artigo foi salientar que, em um momento em que já não se pode trabalhar com as noções de socialização e de instituição como se fazia antes, ${ }^{10}$ a sociologia da educação deve ser pensada como elo fundamental de uma rede sociotécnica, que reúne outros domínios de conhecimento, acadêmicos e não acadêmicos. Nesse sentido, seu lugar bem pode ser concebido como o da mediação entre os diferentes atores que fazem o mundo escolar, aí incluídos os pesquisadores das diferentes áreas. Com isso, as questões propriamente escolares certamente poderão reverberar mais na agenda da sociologia.

\footnotetext{
10 Sobre isso, ver as conhecidas formulações críticas do uso desses conceitos, elaboradas por Touraine (2003) e Dubet (1994).
} 
É evidente que essa concepção só faz sentido porque se parte de um princípio político de que a sociologia deve ser solidária a um projeto de país, norteado pela crença de que o direito a ter direitos é o fundamento do exercício pleno da cidadania; de que essa crença tem na educação escolar um de seus pilares fundamentais. De que, por isso mesmo, a sociologia tem também sua parcela de responsabilidade, seja na capacidade de as escolas responderem às expectativas que as famílias populares nutrem, cada vez mais, pela escolarização longeva de seus filhos; seja pela tarefa de oferecer respostas capazes de melhorar a forma como as escolas enfrentam os desafios inerentes à escolarização de crianças e adolescentes que vivem em contextos muito hostis à sua educabilidade. Além disso, ela também deve estar comprometida com o projeto de afirmação da cidadania da criança, que passa muito fortemente pelo direito à aprendizagem e pelo sistema de proteção que gravita em torno da escola.

Uma sociologia da educação responsável, ainda, por iluminar os efeitos não desejáveis de uma escola que contribui para produzir desigualdades e exclusão não apenas em seu interior, para lembrar um conhecido texto de Bourdieu (1997), mas também na conformação de novas formas de desigualdade, que têm a ver com as diferenças na qualidade da relação com a escola construída por jovens da mesma classe social e moradores dos mesmos lugares, aos quais a evasão precoce (às vezes velada por uma frequência intermitente à escola) denota sua forma mais visível de exclusão.

Cada um dos três eixos aqui enunciados, entre outros que poderiam ser mobilizados, carrega consigo uma trama que não pode ser estudada e tocada pela sociologia se não por meio de um esforço que, com Durkheim, evoque o lugar fundamental dos sistemas educacionais para qualquer sociedade; esses eixos também conformam ideais de sociedade, bem como conflitos e contradições, que ganham novos rounds com a chegada à arena educacional de novos públicos. 
No caso brasileiro, não resta dúvida, a escola pública e seu projeto republicano e democrático estão no centro de graves ataques, que questionam sua autonomia e sua laicidade. É nossa tarefa, enquanto sociólogos, tornar inteligível como e por que chegamos a isso, bem como contribuir para o fortalecimento técnico, cultural, político e institucional das agências educacionais, afinal, delas dependem muito as melhores promessas de nosso projeto de democracia.

O tom crítico em face da produção da sociologia da educação adotado neste texto de modo algum significa subestimar a importância das contribuições realizadas até aqui. Ao contrário, partilhamos da visão de Almeida e Hey de que, pelo menos desde os anos de 2000, concomitantemente à afirmação da presença da escola na vida popular, tem havido uma espécie de redescoberta da escola por parte da sociologia, e de que isso aponta para o encurtamento da "distância entre as explicações baseadas na classe social de origem dos alunos e aquelas centradas nas condições de escolarização a que esses estão submetidos" (Almeida e Hey, 2018, p. 275). Disso resultaria um crescente esforço de pesquisa com base em "grades analíticas multidimensionais", que, para as autoras, já vem permitindo que "as dinâmicas escolares brasileiras" passem a ser "expostas de maneira mais densa, menos comprimidas nos modelos explicativos e analíticos formulados para outros contextos" (Almeida e Hey, 2018, p. 276).

Este texto pretende ser uma contribuição nessa direção.

\section{Marcelo Baumann Burgos}

Doutor em sociologia (Iuperj/Ucam), professor do Departamento de Ciências Sociais da PUC-Rio e pesquisador da Fundação Caed. Tem realizado pesquisas nas áreas de sociologia da educação, sociologia urbana e sociologia do direito. Além de diversos artigos, publicou os livros A escola e a favela (coorganizado por Angela Randolpho Paiva, Pallas/PUC-Rio, 2009) e A escola e o mundo do aluno (Garamond, 2014). 


\section{Bibliografia}

ALMEIDA, Ana Maria Fonseca; HEY, Ana Paula. 2018. Sociologia da educação: olhares sobre um campo em ascensão. In: MICELI, S.; MARTINS, Carlos B. (org.). Sociologia brasileira Hoje II. São Paulo: Ateliê. pp. 253-278.

BITTAR, Mariana. 2011. Trajetórias educacionais dos jovens residentes num distrito com elevada vulnerabilidade juvenil. Tese de Doutorado em Ciência Política. São Paulo: Edusp.

BOURDIEU, Pierre. 1997. A miséria do mundo. Petrópolis: Vozes.

BOURDIEU, Pierre. 2003. O poder simbólico. Rio de Janeiro: Bertrand Brasil. BOURDIEU, Pierre; PASSERON, Jean-Claude. 1992. A reprodução. 3. ed. Rio de Janeiro: Francisco Alves.

BURGOS, Marcelo Baumann (coord.). 2014. A escola e o mundo do aluno: estudos sobre a construção social do aluno e o papel institucional da escola. Rio de Janeiro: Garamond.

BURGOS, Marcelo Baumann. 2020. Redes de proteção dos direitos das crianças: a perspectiva de seus operadores. Tempo Social. No prelo.

BURGOS, Marcelo Baumann; BELLATO, Caíque. 2019. Gerencialismo e pós-gerencialismo: em busca de uma nova imaginação para as políticas educacionais no Brasil. Sociologia E Antropologia, v. 9, n. 3, pp. 919-943.

CAMASMIE, Mariana Junqueira. 2018. O movimento de ocupação das escolas e as novas formas de fruição da juventude escolarizada nas classes populares do Brasil. Dissertação de Mestrado em Ciências Sociais. Rio de Janeiro: PPGCS/PUC-Rio.

CAMPOS, Antonia; MEDEIROS, Jonas; RIBEIRO, Márcio M. 2016. Escolas de luta. São Paulo: Veneta.

CARDOSO, Adalberto. 2013. Retratos da juventude brasileira: elementos para uma agenda de investigação. Caderno CRH, v. 26, n. 68, pp. 293-314. DUBET, François. 1994. Sociologia da experiência. Lisboa: Instituto Piaget. DUBET, François. 2008. O que é uma escola justa? São Paulo: Cortez.

DURKHEIM, Émile. 1968. Educação e sociologia. 7. ed. São Paulo: Melhoramentos. DURKHEIM, Émile. 1995. A evolução pedagógica. Porto Alegre: Artes Médicas.

DUSI, Cristina Sayuri Côrtes Ouchi. 2017. Os efeitos da gestão para resultados na educação: uma análise das políticas públicas educacionais de sete estados brasileiros. Tese de Doutorado em Ciências Sociais. Rio de Janeiro: PPGCS/PUC-Rio.

FELTRAN, Gabriel. 2014. O valor dos pobres: a aposta no dinheiro como mediação para o conflito social contemporâneo. Caderno CRH, v. 27, n. 72, pp. 495-512. 
FITOUSSI, Jean-Paul; ROSANVALLON, Pierre. 1997. A nova era das desigualdades. Oeiras: Celta.

GIDDENS, Anthony. 2013. A constituição da sociedade. 3. ed. São Paulo: Martins Fontes.

HARGREAVES, Andy et al. (eds.). 2010. Second International Handbook of Educational Change. New York: Springer.

LOPEZ, Néstor. 2005. Equidad educativa y desigualdad social: desafios a la educación en el nuevo escenario latinoamericano. Buenos Aires: Iipe/Unesco.

OLIVEIRA, Amurabi; FERREIRA DA SILVA, Camila. 2016. A sociologia, os sociólogos e a educação no Brasil. Revista Brasileira de Ciências Sociais, v. 31, n. 91 .

PEREGRINO, Mônica. 2010. Trajetórias desiguais: um estudo sobre os processos de escolarização pública de jovens pobres. Rio de Janeiro: Garamond.

RAMOS, Alberto Guerreiro. 1965. A redução sociológica: introdução ao estudo da razão sociológica. Rio de Janeiro: Tempo Brasileiro.

ROSEMBERG, Fúlvia. 2008. Crianças e adolescentes na sociedade brasileira e a Constituição de 1988. In: BRANDÃO, Gildo Marçal; OLIVEN, Ruben George; RIDENTI, Marcelo (org.). A Constituição de 1988 na vida brasileira. São Paulo: Anpocs.

TELLES, Vera da Silva. 2010. Nas dobras do legal e do ilegal: ilegalismos e jogos de poder nas tramas da cidade. Dilemas: Revista de Estudos de Conflito e Controle Social, v. 2, n. 5-6, pp. 97-127.

TOURAINE, Alain. 2003. Poderemos viver juntos? Iguais e diferentes. 2. ed. Petrópolis: Vozes.

UNICEF. 2015. ECA: 25 anos de Estatuto da Criança e do Adolescente. Avanços e desafios para a infância e a adolescência no Brasil. Disponível em: https://uni.cf/2YxLLaV. Acesso em: 12 dez. 2015.

UNICEF. 2019. A educação que protege contra a violência. Brochura.

VINCENT, Guy; LAHIRE, Bernard; THIN, Daniel. 2001. Sobre a história e a teoria da forma escolar. Educação em Revista, n. 33. Disponível em: https://bit.ly/321SV2T. Acesso em: 13 ago. 2020.

WILLIS, Paul. 1991. Aprendendo a ser trabalhador: escola, resistência e reprodução social. Porto Alegre: Artes Médicas. 


\section{A DUPLA HERMENÊUTICA DA SOCIOLOGIA DA EDUCAÇ̃̃O: A EDUCAÇÃO DAS NOVAS GERAÇÕES E A ORGANIZAÇÃ̃O ESCOLAR} MARCELO BAUMANN BURGOS

Resumo: A relação entre a sociologia e a área da educação tem sido atravessada por fronteiras mal compreendidas, que comprometem a complementariedade entre elas. No caso brasileiro, essa situação tem deixado expostas dimensões sociológicas que fazem falta aos profissionais da escola. Neste texto, abordamos essa questão situando o debate a partir da noção de "dupla hermenêutica", nos termos de Giddens, a fim de delimitar o problema da responsabilidade da sociologia com as questões propriamente escolares. Para melhor expor a proposta, o artigo explora três eixos analíticos, a saber: o processo de afirmação da educação escolar como um valor cada vez mais importante na vida popular; os conflitos entre a escola e os direitos das crianças vigentes desde o ECA; e as novas formas de desigualdade produzidas pela escola na trajetória de jovens de classes populares.

Palavras-chave: Sociologia da Educação; Escola; Cidade; Desigualdade Social.

\section{THE DOUBLE HERMENEUTIC OF SOCIOLOGY OF EDUCATION: THE NEW GENERATION'S EDUCATION AND SCHOOL'S ORGANIZATION}

Abstract: A relationship between sociology and an area of education was crossed by misunderstood boundaries, compromising their complementarity. In the case of Brazil, this situation produces gaps that undermine the work of school professionals. We address this issue according to the notion of "double hermeneutics, "in Giddens's terms, to delimit the problem of sociological responsibility with actual school matters. Three analytical axes are explored, namely: how school education has acquired more value in popular life; 
the conflicts between school and children's rights in force since ECA; and the new forms of inequality produced by the school in the trajectory of young people of low income classes.

Keywords: Sociology of Education; School; City; Social Inequality.

Recebido: 20/10/2019 Aprovado: 05/08/2020 